\title{
Pediatric musculoskeletal pain in the emergency department: a medical record review of practice variation
}

\author{
Janeva Kircher, $\mathrm{MD}^{*}$; Amy L. Drendel, DO, $\mathrm{MS}^{\dagger}$; Amanda S. Newton, $\mathrm{PhD}, \mathrm{RN}^{\ddagger \S}$; \\ Sukhdeep Dulai, MD"; Ben Vandermeer, $\mathrm{MSc}^{\S}$; Samina Ali, MDCM${ }^{* £ \S}$
}

\section{ABSTRACT}

Objective: Musculoskeletal (MSK) injuries are a common, painful pediatric presentation to the emergency department (ED). The primary objective of this study was to describe current analgesic administration practices for the outpatient management of children's MSK pain, both in the ED and postdischarge.

Methods: We reviewed the medical records of consecutive pediatric patients evaluated in either a pediatric or a general ED (Edmonton, Alberta) during four evenly distributed calendar months, with a diagnosis of fracture, dislocation, strain, or sprain of a limb. Abstracted data included demographics, administered analgesics, pain scores, discharge medication advice, and timing of clinical care.

Results: A total of 543 medical records were reviewed ( $n=$ 468 pediatric ED, $n=75$ general ED). Nineteen percent had documented prehospital analgesics, 34\% had documented in-ED analgesics, $13 \%$ reported procedural sedation, and $24 \%$ documented discharge analgesia advice. Of those children receiving analgesics in the ED, 59\% (126 of 214) received ibuprofen. Pain scores were recorded for $6 \%$ of patients. At discharge, ibuprofen was recommended to $47 \%$ and codeine-containing compounds to $21 \%$ of children. The average time from triage to first analgesic in the ED was $121 \pm 84$ minutes.

Conclusions: Documentation of the assessment and management of children's pain in the ED is poor, and pain management appears to be suboptimal. When provided, ibuprofen is the most common analgesic used for children with MSK pain. Pediatric patients with MSK pain do not receive timely medication, and interventions must be developed to improve the "door to analgesia" time for children in pain.
RÉSUMÉ

Objectif: Les blessures musculosquelettiques (MS) douloureuses chez les enfants sont un motif fréquent de consultation au service des urgences (SU). L'étude avait pour objectif principal de décrire les pratiques actuelles de l'administration des analgésiques dans la prise en charge des douleurs MS, en mode ambulatoire, tant au SU qu'à domicile, après le congé de I'hôpital.

Méthode: Ont été passés en revue les dossiers médicaux d'enfants consécutifs, examinés dans un SU général ou un SU pédiatrique (Edmonton [Alberta]) au cours de quatre mois civils répartis également, pour un diagnostic de fracture, de dislocation, de foulure ou d'entorse d'un membre. Les renseignements recueillis comprenaient des données démographiques, les analgésiques administrés, les cotes de la douleur, les conseils sur les médicaments donnés au moment du congé et la durée des soins cliniques.

Résultats: Au total, 543 dossiers médicaux ont été examinés ( $n=468$ au SU pédiatrique; $n=75$ au SU général). Dans 19\% d'entre eux était consignée la prise d'analgésiques en phase préhospitalière; dans 34\%, l'administration d'analgésiques au SU; dans $13 \%$, I'administration de sédation-analgésie à des fins interventionnelles; et dans $24 \%$, la prestation de conseils sur l'analgésie au moment du congé. Parmi les enfants à qui I'on a prescrit des analgésiques au SU, 59\% (126 sur 214) ont reçu de l'ibuprofène. Des cotes de la douleur ont été consignées chez $6 \%$ des patients. Au moment du congé, l'ibuprofène a été recommandé chez $47 \%$ des enfants et des composés à base de codéine, chez $21 \%$ des enfants. Le temps moyen écoulé depuis le triage jusqu'à I'administration du premier analgésique au SU était de $121 \pm 84$ minutes.

Conclusions: D'après la documentation recueillie, l'évaluation et la prise en charge de la douleur laissent à désirer chez

From the *Department of Emergency Medicine, Faculty of Medicine and Dentistry, University of Alberta, Edmonton, AB; tDepartment of Pediatrics, Children's Hospital of Wisconsin, Medical College of Wisconsin, Milwaukee, Wl; $¥$ Women and Children's Health Research Institute, Edmonton, AB; $\S$ Department of Pediatrics, Faculty of Medicine and Dentistry, University of Alberta, Edmonton, AB; ॥Department of Surgery, University of Alberta, Edmonton, $\mathrm{AB}$.

Correspondence to: Dr. Samina Ali, Department of Pediatrics, Edmonton Clinic Health Academy, 11405 - 87 Avenue, Edmonton, AB T6G 1C9; sali@ualberta.ca.

This article has been peer reviewed. 
les enfants, au SU, et le traitement de la douleur ne semble pas optimal. Le cas échéant, l'ibuprofène est l'analgésique prescrit le plus souvent aux enfants qui présentent des douleurs MS. Bref, I'administration de médicaments chez ces enfants tarde, et il faut élaborer des interventions afin de raccourcir la période d'attente de l'analgésie chez les enfants qui éprouvent des douleurs.

Keywords: emergency, fracture, musculoskeletal, pain, pediatric
Acute musculoskeletal (MSK) injuries are among the most common presentations to the emergency department (ED), accounting for $25 \%$ of diagnoses following an acute injury. ${ }^{1,2} \mathrm{~A}$ child's risk of sustaining a fracture before the age of 16 years ranges from 27 to $42 \% .^{3-5}$ Both the injury itself and the required interventions (i.e., cast application) can be painful, with most children who have sustained limb trauma reporting moderate pain in the ED and after discharge. ${ }^{6-8}$

The World Health Organization (WHO) has declared that pediatric pain treatment is a public health concern of major significance. ${ }^{9}$ Inadequate pain treatment during medical care, especially among young children, can have numerous detrimental effects. It can result in extended length of stay, slower healing, and emotional trauma. ${ }^{10}$ Negative effects can extend to adulthood and include fear of medical events or health care consultations, avoidance or overuse of medical care, and heightened sensitivity to subsequent medical care. $^{11,12}$

ED management of children's pain remains suboptimal. ${ }^{13-22}$ MSK pain in very young children has been found to be particularly undertreated when compared to MSK pain in school-aged children. ${ }^{23}$ To create system improvements in pain management, it is first important to define the analgesic practice patterns of physicians treating pediatric MSK injuries in Canadian EDs. To date, few studies have examined these patterns; within those studies, the exact pharmacologic agents prescribed are not routinely reported. ${ }^{13-17}$ This study examined pediatric patients presenting with acute MSK pain at two tertiary care EDs in Edmonton, Alberta.

\section{MATERIALS AND METHODS}

\section{Study design and setting}

This medical record review identified pediatric patients who presented to the Stollery Children's Hospital and the Royal Alexandra Hospital in Edmonton, Alberta. The Stollery Children's Hospital is a 152-bed facility that provides services to children in an area covering northern
Alberta, parts of British Columbia, Saskatchewan, the Northwest Territories, Yukon, and Nunavut. The pediatric emergency department (PED) serves children exclusively and is located on a university campus with a mid-to-higher socioeconomic status (SES). The PED has a yearly census of approximately 38,000 patients age 0 to 16 years. In 2008, 1,382 visits were for acute MSK injury in children age 3 to 16 years who were discharged. The Royal Alexandra Hospital is a general emergency department (GED) with approximately 66,000 visits per year. The GED serves a population of lower SES and has a much smaller pediatric census than the PED. In 2008, 259 GED visits were for acute MSK injury in children age 3 to 16 years who were discharged. Both sites have mandatory recording of Canadian Triage and Acuity Scale (CTAS) classification, dose, timing, type of medication given, and timing of all interventions. Pain scores, pain reassessment, and nonpharmacologic pain management recording were nonmandatory values at the time of the study.

This study was approved by the University of Alberta Health Research Ethics Board.

\section{Case selection}

To capture seasonal and temporal variations in the presentation of MSK injuries, consecutive medical records of patients who presented to the EDs during the months of January, April, July, and October 2008 (over 24 hours per day) were studied. Records were selected based on the International Statistical Classification of Diseases and Related Health Problems, Tenth Revision, Canada (ICD-10-CA) codes and captured patients with limb fractures, sprains, strains, and dislocations (S42: Fracture of shoulder and upper arm; S52: Fracture of forearm; S62: Fracture at wrist and hand level; S82: Fracture of lower leg, including ankle; S92: Fracture of foot, except ankle; S43: Dislocation, sprain and strain of joints and ligaments of the shoulder girdle; S53: Dislocation, sprain and strain of joints and ligaments of elbow; S63: Dislocation, sprain and strain of joints and ligaments at wrist and hand level; S83: Dislocation, sprain and strain of joints and 
ligaments of knee; and S93: Dislocation, sprain and strain of joints and ligaments at ankle and foot level). Charts were excluded if the patient was 17 years or older, required hospital admission, had an injury greater than 72 hours old, had a pre-existing bone or metabolic disease (e.g., osteogenesis imperfecta), had any injury to the axial skeleton (spine, head, or pelvis), or had multiple injuries (defined as three or more ICD10-CA codes).

\section{Study protocol}

This study followed Gilbert and colleagues' recommended methodological guidelines for emergency medicine chart reviews. ${ }^{24} \mathrm{~A}$ study-specific abstraction template was designed and used for data collection. Prior to use, it was piloted to assess the feasibility of the planned investigation, availability of data for abstraction, and identification of any sampling concerns, as indicated by Gearing and colleagues. ${ }^{25} \mathrm{~A}$ single trained abstractor (Y.K.) who was blinded to the study hypothesis performed data abstraction. The data abstractor had close communication with the study team to address any issues.

\section{Measurements}

For each case, the following data points were collected: patient demographics (age, sex, first three digits of the postal code, CTAS score), prehospital analgesic use (drug, dose, provider), ED analgesic use (including those used for procedural sedation [drug, dose, provider, time of administration]), use of nonpharmacologic pain management techniques (casting, splinting), pain assessment (tool, score, time, reassessment), department flow times (time of triage, first nurse assessment, first physician assessment, discharge), and recommended analgesic at discharge. Prehospital analgesic was defined as medication administered to the patient by the patient, the patient's caregivers, or prehospital medical personnel. Postal codes were collected and used as a proxy for SES. ${ }^{26}$ This was accomplished by correlating the first three digits of the postal code with median annual household income data from the Statistics Canada database (2008). Income categories were based on tax brackets from the Canadian Revenue Agency data (2008). For pain assessment, a score of 0 to 3 was considered mild, 4 to 6 moderate, and 7 to 10 severe, as per the WHO's pain ladder. ${ }^{9}$
For patients whose weight was missing from the chart $(n=51)$, the 50th percentile weight for the patient's age was used for calculation of drug dose per kilogram, obtained from gender-appropriate Centers for Disease Control and Prevention growth charts. ${ }^{27}$

\section{Statistical tests}

Means were computed for continuous data (e.g., age), whereas proportions were calculated for dichotomous data (e.g., sex). Confidence intervals (95\%) of means were computed using the normal distribution, whereas those for proportions were computed using the normal scores method. The $p$ values comparing two means were computed using an unpaired $t$-test, whereas those between proportions were computed using the Fisher exact test. For ordinal data (e.g., income level), the Kruskal-Wallis test was used to compare significance between two groups, whereas for categorical data (e.g., final diagnosis), the Fisher-Freeman-Halton test was used.

\section{RESULTS}

The medical records for 543 patients were retrieved: 468 from the PED and 75 from the GED. This ratio is representative of the pediatric census ratio for the two EDs studied. Patient demographic and clinical characteristics are reported in Table 1. Upper limb injuries (50.6\% sustained a fracture and $16.9 \%$ a sprain, strain, or dislocation) were more common than lower limb injuries $(16.6 \%$ sustained a sprain, strain, or dislocation and $15.8 \%$ a fracture). Patients presenting to the GED were of lower SES than patients presenting to the PED $(p<0.00001)$. Medication use differed significantly between the GED and the PED, with more children at the $\mathrm{PED}$ receiving prehospital analgesics, analgesics in the ED, and procedural sedation. More children at the GED received discharge pain management advice (Table 2).

\section{Prehospital analgesics}

Prehospital analgesic use was documented for $21.8 \%$ $(n=102)$ of PED patients and 1 GED patient. Of these patients, $27.2 \%$ received the analgesics from prehospital medical personnel, $14.0 \%$ received it from another hospital, and for the remainder, it was unclear or not documented. The proportions of children 


\begin{tabular}{|lcc|}
\hline Table 1. Demographic characteristics of patients & & \\
\hline Characteristic & PED $(n=468)$ & GED $(n=75)$ \\
\hline Mean age, yr $(95 \%$ CI) & $9.3(8.8,9.7)$ & $10.6(9.5,11.7)$ \\
Male, $n(\%)$ & $301(64.3)$ & $39(52.0)$ \\
Fracture, $n(\%)$ & $309(66.0)$ & $52(69.3)$ \\
Sprain, strain, or dislocation, $n(\%)$ & $159(34.0)$ & $23(30.7)$ \\
CTAS score, $n(\%)$ & & $12(16.0)$ \\
1 & $0(0)$ & $34(45.3)$ \\
2 & $35(7.5)$ & $28(37.3)$ \\
3 & $297(63.5)$ & $1(1.3)$ \\
4 & $128(27.4)$ & $0.03^{*}$ \\
5 & $7(1.5)$ & 0.06 \\
Unknown & $1(0.2)$ & 0.6 \\
\hline CTAS = Canadian Acuity and Triage Scale; GED = general emergency department; PED $=$ pediatric emergency department.
\end{tabular}

receiving each analgesic agent are shown in Figure 1A, and the dosages administered are presented in Table 3. Age and gender were not found to influence the likelihood of receiving prehospital analgesics $(p=0.96$ and 0.52 , respectively).

\section{Analgesics in the ED}

Overall, $33.5 \%$ of children with MSK injury were administered analgesic agents in the ED. The proportions of children receiving each analgesic agent are shown in Figure 1B, and the dosages administered are found in Table 3. Thirteen percent of patients underwent procedural sedation for fracture management. Across both sites, propofol was used in $90.3 \%$ of patients, fentanyl in $73.6 \%$, ketamine in $25 \%$, and "ketofol" (a 50:50 mixture of ketamine and propofol) in $1.4 \%$. Medication choice was not affected by month, time of day, SES, age of the patient, or site of injury ( $p=0.72,0.82,0.35,0.7$, and 0.23 , respectively).

A minority of children received an analgesic of any kind. More children with fractures versus sprains, strains, or dislocations received analgesics in the PED (39.7\% versus $17.3 \%, p=0.03)$, although more children with sprains, strains, or dislocations received analgesics in the GED than in the PED (43.5\% versus $25.2 \%, p=0.03)$. Male patients were significantly more likely to be given analgesics than females $(39 \%$ versus $25 \%, p=0.001)$. Patients with a higher acuity triage score were significantly more likely to be given analgesics $(p=0.000003)$.

\section{Discharge analgesics}

Across both sites, $23.8 \%$ of children had a documented discharge analgesic recommendation on their chart. Ibuprofen was the most commonly recommended analgesic. The proportions of children receiving each analgesic agent are shown in Figure 1C. An analgesic at discharge was recommended for more children in the GED than in the PED (GED 34.7\%, PED 22.0\%).

No statistical differences were seen in the recommended discharge analgesics between upper limb versus lower limb injuries $(p=0.61)$. Recommended

\begin{tabular}{|lcc|}
\hline Table 2. Pattern of medication use for musculoskeletal injuries & \\
\hline & PED, $n(\%)(n=468)$ & GED, $n(\%)(n=75)$ \\
\hline Prehospital medication & $102(21.8)$ & $1(1.3)$ \\
ED medication & $163(34.8)$ & $19(25.3)$ \\
Procedural sedation & $68(14.5)$ & $4(5.3)$ \\
Discharge medication & $103(22.0)$ & $26(34.7)$ \\
\hline ED = emergency department; GED $=$ general emergency department; PED = pediatric emergency department. \\
\hline$p<0.00001$ (Fisher-Freeman-Halton).
\end{tabular}


A

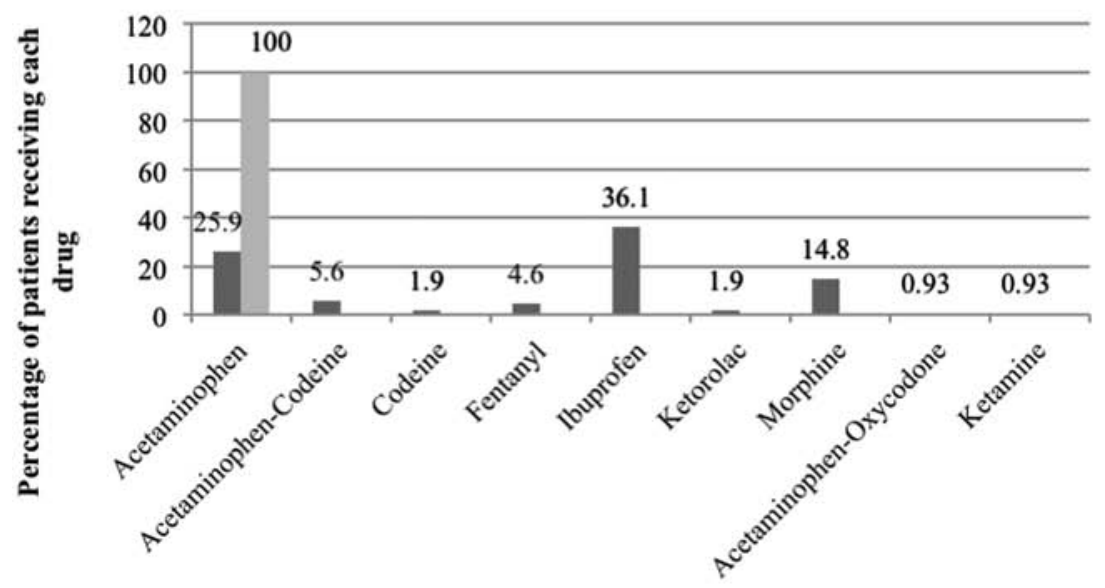

- PED n=108

GED $\mathrm{n}=1$

Drug

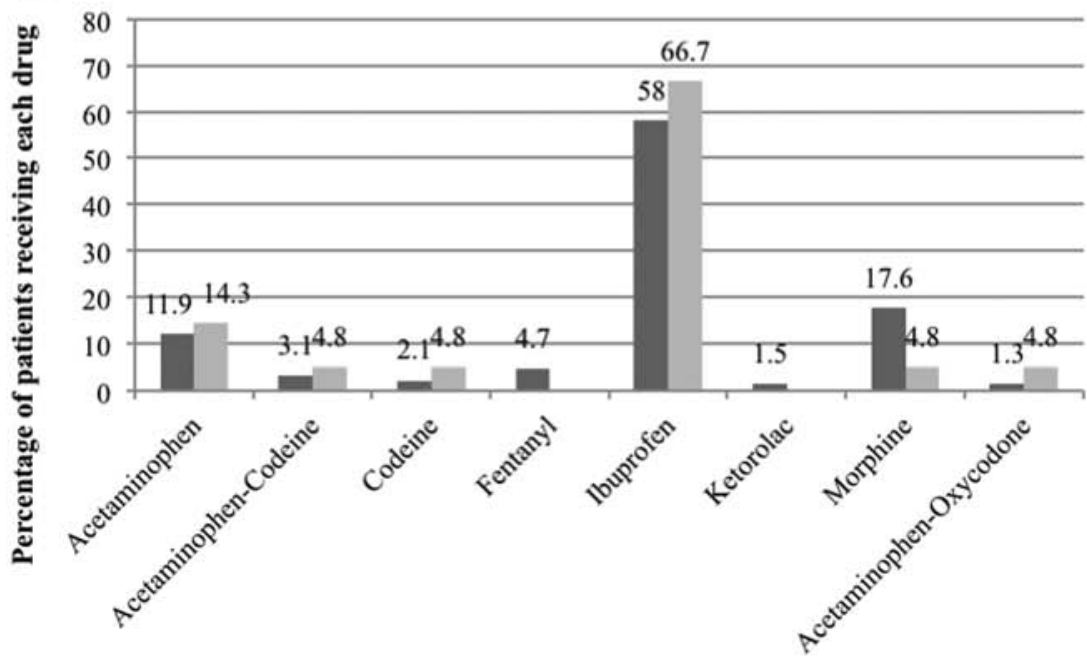

Drug

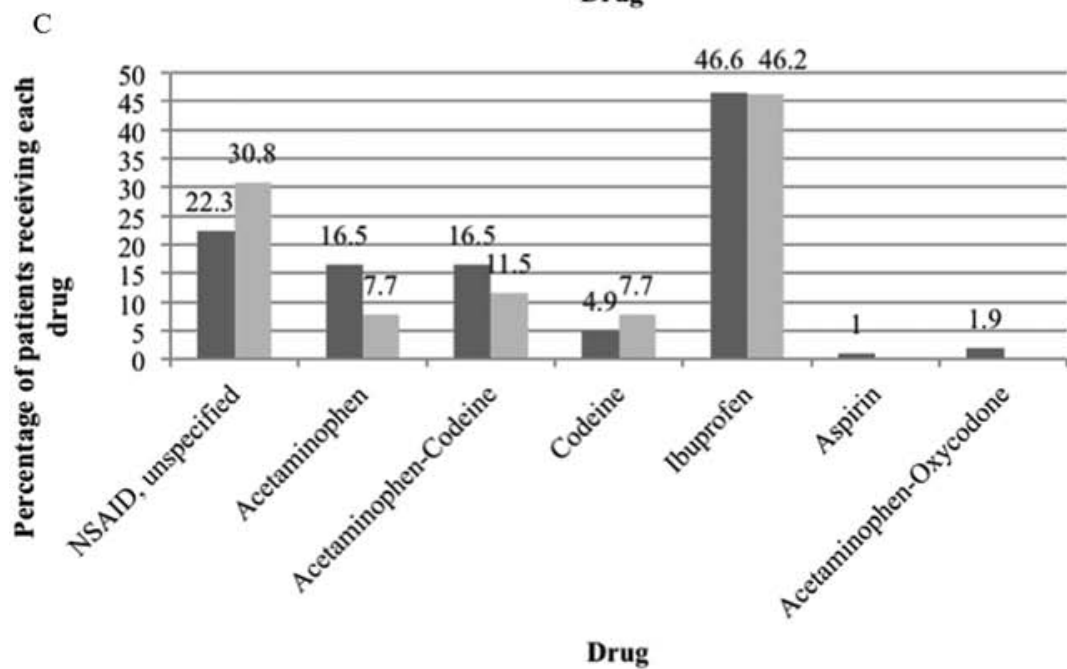

mED $n=193$

w GED $\mathrm{n}=21$

-PED $\mathrm{n}=103$

$=$ GED $\mathrm{n}=26$

Figure 1. $A$, Percentage of children documented as having received each medication in the prehospital setting. $B$, Percentage of children documented as having received each medication within the emergency department. $C$, Medication recommendations at the time of discharge. GED = general emergency department; NSAID = nonsteroidal antiinflammatory drug; PED = pediatric emergency department. 
Table 3. Proportion of children with documented incorrect medication dose, both sites

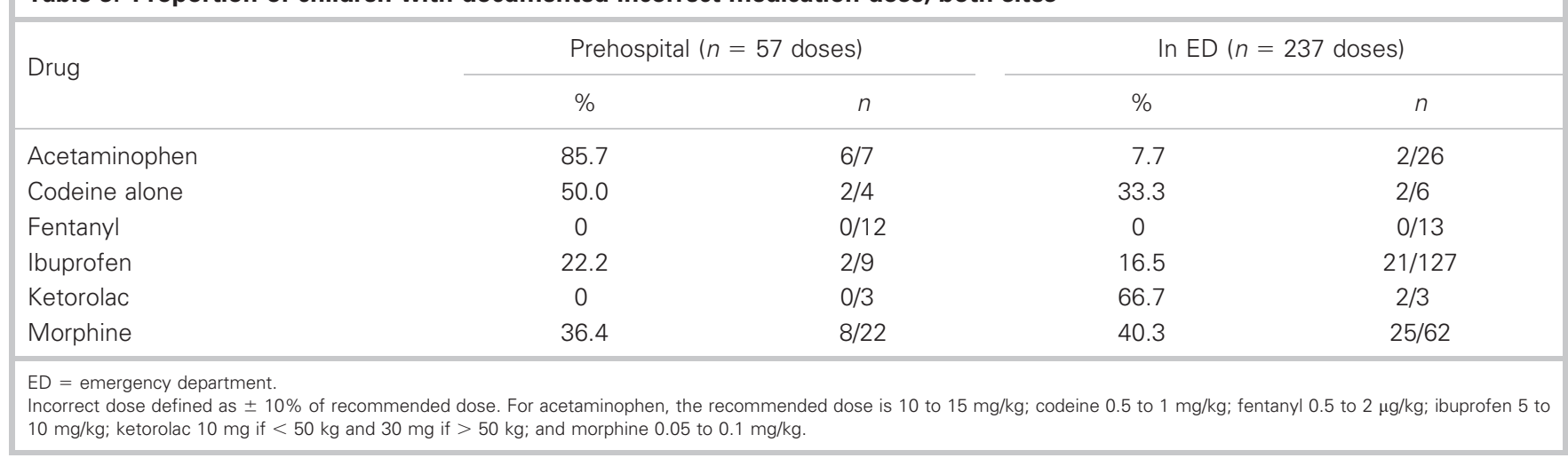

discharge analgesics did not differ for patients with fracture who did or did not require procedural sedation $(p=0.26)$. More children in the PED had documented discharge analgesic recommendations with a sprain, strain, or dislocation than fracture $(28.3 \%$ versus $18.8 \%, p=0.01)$; this difference was not demonstrated in the GED setting $(p=0.57)$. Patients who underwent procedural sedation were equally likely as those who did not to have a discharge analgesic recommendation documented $(p=1.0)$.

\section{Emergency department flow}

Children in the PED had a greater overall length of stay, but children in the GED waited 55 minutes longer, on average, to receive their first assessment by an ED nurse and 70 minutes longer, on average, to receive their first assessment by an ED physician. The results are shown in Table 4. There was no evidence that SES was associated with time to ED nurse assessment (Spearman correlation: -0.04 [-0.14, $0.06])$; however, the time to discharge was shorter for those with a higher SES (Spearman correlation: -0.10 $[-0.19,-0.02])$.

\section{Pain scores}

Pain scores were recorded in $6.2 \%$ of PED patients $(n=29)$ and $2.7 \%$ of GED patients $(n=2)$. Initial pain scores were not statistically different between each site $(p=0.23)$. The most frequently used pain assessment tool was the verbal numerical rating scale (95.6\% of assessments). Reassessment of pain score was documented in $27.6 \%(n=8)$ of children in the PED; however, no repeat pain scores were documented in the GED.

\section{DISCUSSION}

Oligoanalgesia remains a problem for pediatric patients in the ED as only one-third of children in this study evaluated for a MSK injury were administered an analgesic, while waiting almost 2 hours to receive it. We know that pain is almost always present

\section{Table 4. Average patient flow times}

\begin{tabular}{|c|c|c|c|}
\hline Time interval & Average time in PED (min, 95\% Cl) & Average time in GED (min, 95\% Cl) & $p$ \\
\hline Triage to ED nurse & $55.9(49.6,62.2)$ & $110.2(79.0,141.3)$ & $0.0008^{*}$ \\
\hline Triage to physician & $73.0(67.0,79.0)$ & $142.6(101.0,184.3)$ & $0.001^{*}$ \\
\hline ED nurse to physician & $27.1(23.0,31.2)$ & $38.8(24.4,53.1)$ & 0.12 \\
\hline Physician to discharge & $119.7(108.7,130.6)$ & $83.9(59.4,108.4)$ & $0.009^{*}$ \\
\hline Triage to discharge & $197.1(185.2,209.0)$ & $209.1(161.8,256.4)$ & 0.63 \\
\hline Triage to ED analgesia & $112.3(100.0,124.5)$ & $196.4(105.7,287.2)$ & 0.07 \\
\hline ED nurse to ED analgesia & $70.2(58.9,81.4)$ & $62.4(31.8,93.0)$ & 0.64 \\
\hline Physician to ED analgesia & $57.5(45.3,69.7)$ & $36.3(13.8,58.8)$ & 0.1 \\
\hline
\end{tabular}


in patients presenting with an injury. Thompson and colleagues showed that children who have suffered an extremity fracture continue to suffer clinically meaningful pain after discharge. ${ }^{28}$ In fact, less than $10 \%$ of children were not given pain medication at home after discharge. ${ }^{8}$ Gill and colleagues prospectively surveyed the families of children with arm fractures and found that more than half of children experienced pain "all the time" or "quite a bit"; $32 \%$ of parents were not satisfied with their child's care. ${ }^{29}$ The strongest predictor of dissatisfaction was their child's report that the analgesic did not relieve the pain.

The injury pattern in our study, with upper limb fractures representing $76 \%$ of fractures, is representative of local provincial injury patterns. Similarly, an international review of approximately 9,000 children's fractures found that upper limb fractures constitute $79 \%$ of extremity fractures. ${ }^{3}$

In our study, only $38.4 \%$ of children in the PED received any analgesic and $22.0 \%$ had documented discharge pain medication recommendations. In the GED, $25.3 \%$ of children received analgesics in the department and $34.7 \%$ had discharge pain medication recommendations documented. This suggests that educational initiatives for emergency physicians should be tailored to their practice setting. These findings are similar to those of Cimpello and colleagues' study, which found that general physicians documented discharge pain medications more often than pediatric physicians, although there was no difference in the frequency of analgesic provision in the ED. ${ }^{15}$

Recently, Dong and colleagues studied children in a PED who required admission with long bone fracture and found that children with upper limb fractures were less likely to receive adequate pain medicine during the ED visit compared to lower limb fractures, a finding not reproduced in our study..$^{30}$ Although our study found that age did not affect the likelihood of receiving analgesics in the ED, Alexander and Manno found that children younger than 2 years received less analgesics than school-aged children with fractures and severe burns. ${ }^{23}$ Of note, the average patient age in our study was approximately 10 years, and the youngest children were likely underrepresented.

In our study, only $22 \%$ of children presenting to the PED and $1 \%$ presenting to the GED received any form of prehospital analgesic. Our findings are similar to those of Kozlowski and colleagues, who found that $25 \%$ of patients had received prehospital analgesics. ${ }^{31}$ Our patients received suboptimal dosing, especially for ibuprofen and acetaminophen. Underdosing may be more likely to occur in the prehospital setting when following manufacturer guidelines as they are based on age rather than weight. It can also be hypothesized that emergency medical services personnel and peripheral hospitals may be less comfortable with children's medication dosing. With respect to caregiver administration of pain medications, Maimon and colleagues found that parents were concerned about masking clinical findings and avoided treating pain. ${ }^{32}$

We found that children in our study waited almost 2 hours to receive any analgesic in the ED. This is greater than the findings in other similar reported studies. Weng and colleagues found that the time to analgesic administration was 70 minutes in a retrospective American study of children with long bone fracture, ${ }^{33}$ and Dong and colleagues found that $59 \%$ of American patients received no analgesic in the first hour..$^{30}$ Interestingly, triage acuity scores were higher in the GED (see Table 1), but we suspect that since children were competing with adults of similar acuity, they likely had to wait longer. Furthermore, overcrowding and wait times, in general, are a greater issue in the GED. This further highlights the need to prioritize children's pain in all settings.

In our study, only $5.7 \%$ of patients had a pain score documented, compared to 44.5 to $87.4 \%$ in American studies. ${ }^{34,35}$ The lack of a Canadian equivalent to the Joint Commission may explain why there is such a marked discrepancy in pain score documentation between Canada and the United States. As most children present with moderate pain due to extremity trauma, ${ }^{7}$ suboptimal pain management as a result of failing to document pain is a possibility.

Several studies have found a reduction in time to analgesic administration after quality improvement interventions. ${ }^{36-38}$ Interventions have included clinical care pathways, standing medication and radiology orders, bedside registration, target setting, continuous feedback and adjustment opportunities, implementing quality improvement methods, which consisted of a pain care team, and educational programs. Given the overall success of these interventions, similar protocols could be instituted in Canadian EDs to optimize the time to analgesia.

The most efficacious analgesic for pediatric MSK pain remains to be determined. To date, ibuprofen has been found to be at least as effective as acetaminophencodeine and codeine alone. ${ }^{39,40}$ Codeine has recently 
become less favourable, considering the high interindividual variability in response due in part to its pharmacogenomics profile. A recent review recommended ibuprofen as the current first-line analgesic for mild to moderate MSK pain ${ }^{39}$; this practice was reflected in our study, with over $50 \%$ of children receiving ibuprofen. However, nearly $10 \%$ of children at the GED received codeine-containing compounds. Overall, opioid medications, in general, were infrequently used in this study, despite being a first-line recommendation for patients with moderate to severe pain. ${ }^{9}$ It is possible that a fear of opioid use (both parental and health care professional) may also be contributing to the undertreatment of pediatric pain.

Pain management should be paramount in the care of a child with MSK injury. From our study, it would seem that much more effort is still required to attain that goal.

\section{LIMITATIONS}

This study has limitations inherent in a medical record review. Data collection was limited to what was recorded in the medical record. Variables such as pain medication administered and time to analgesic are not subject to this limitation; however, other variables, such as pain assessments, discharge advice, and patient or caregiver refusal of analgesic, may have occurred but not been documented on the chart.

Although this study only recorded nonpharmacologic interventions of casting and splinting, analgesia can also be provided by other means, such as ice and elevation. Although these other measures may decrease pain, they do not necessarily obviate the need for medication.

We also acknowledge that a shift in medication administration practices may have occurred in the period of time between data collection and study publication. Lastly, this study was conducted at two teaching hospitals in Canada and may not be generalizable to all populations.

\section{CONCLUSION}

Documentation of the assessment and management of children's pain in the ED is poor, and pain management appears to be suboptimal. Children have to wait prolonged periods of time to receive pain medication, and, overall, too few receive any analgesic in the ED.
Documentation of pain assessment occurs infrequently and may contribute to the undertreatment of pain.

Acknowledgements: We would like to acknowledge the contributions of Yvonne Klatt for performing the data management, Melissa Gutland for administrative support, and Erin Logue for project coordination. We would also like to thank the Women and Children's Health Research Institute and the Alberta Research Centre for Health Evidence for biostatistical support.

Competing interests: Dr. Amanda Newton is supported by a New Investigator Award from the Canadian Institutes of Health Research (2012-2017).

\section{REFERENCES}

1. Kennedy RM, Luhmann JD, Luhmann SJ. Emergency department management of pain and anxiety related to orthopedic fracture care: a guide to analgesic techniques and procedural sedation in children. Paediatr Drugs 2004;6:1131, doi:10.2165/00148581-200406010-00002.

2. Spady DW, Saunders DL, Schopflocher DP, et al. Patterns of injury in children: a population-based approach. Pediatrics 2004;113(3 Pt 1):522-9, doi:10.1542/peds.113.3.522.

3. Landin LA. Epidemiology of children's fractures. 7 Pediatr Orthop B 1997;6:79-83, doi:10.1097/01202412-199704000$\underline{00002}$.

4. Rennie L, Court-Brown CM, Mok JY, et al. The epidemiology of fractures in children. Injury 2007;38:91322, doi:10.1016/i.injury.2007.01.036.

5. Cooper C, Dennison EM, Leufkens HG, et al. Epidemiology of childhood fractures in Britain: a study using the general practice research database. 7 Bone Miner Res 2004;19:1976-81, doi: $10.1359 / \mathrm{jbmr} .040902$.

6. Migita RT, Klein EJ, Garrison MM. Sedation and analgesia for pediatric fracture reduction in the emergency department: a systematic review. Arch Pediatr Adolesc Med 2006;160:46-51, doi:10.1001/archpedi.160.1.46.

7. Clark E, Plint AC, Correll R, et al. A randomized, controlled trial of acetaminophen, ibuprofen, and codeine for acute pain relief in children with musculoskeletal trauma. Pediatrics 2007;119:460-7, doi:10.1542/peds.2006-1347.

8. Drendel AL, Gorelick MH, Weisman SJ, et al. A randomized clinical trial of ibuprofen versus acetaminophen with codeine for acute pediatric arm fracture pain. Ann Emerg Med 2009; 54:553-60, doi:10.1016/j.annemergmed.2009.06.005.

9. World Health Organization. WHO guidelines on the pharmacological treatment of persisting pain in children with medical illnesses. 2012. Available at: http://apps.who.int/iris/bitstream/10665/ 44540/1/9789241548120_Guidelines.pdf (accessed October 2012).

10. Megel ME, Houser CW, Gleaves LS. Children's responses to immunizations: lullabies as a distraction. Issues Compr Pediatr Nurs 1998;21:129-45, doi:10.1080/014608698265456.

11. Curry SL, Russ SW. Identifying coping strategies in children. f Clin Child Psychol 1985;14:61-8, doi:10.1207/ $\underline{\text { s15374424jiccp1401_10. }}$. 
12. Pate JT, Blount RL, Cohen LL, Smith AJ. Childhood medical experience and temperament as predictors of adult functioning in medical situations. Child Health Care 1996;25: 281-98, doi:10.1207/s15326888chc2504_4.

13. O'Donnell J, Ferguson LP, Beattie TF. Use of analgesia in a paediatric accident and emergency department following limb trauma. Eur F Emerg Med 2002;9:5-8, doi:10.1097/00063110200203000-00003.

14. Brown JC, Klein EJ, Lewis CW, et al. Emergency department analgesia for fracture pain. Ann Emerg Med 2003;42:197-205, doi:10.1067/mem.2003.275.

15. Cimpello LB, Khine H, Avner JR. Practice patterns of pediatric versus general emergency physicians for pain management of fractures in pediatric patients. Pediatr Emerg Care 2004;20:228 32, doi:10.1097/01.pec.0000121242.99242.e0.

16. Petrack EM, Christopher NC, Kriwinsky J. Pain management in the emergency department: patterns of analgesic utilization. Pediatrics 1997;99:711-4, doi:10.1542/peds.99.5.711.

17. Ngai B, Ducharme J. Documented use of analgesics in the emergency department and upon release of patients with extremity fractures. Acad Emerg Med 1997;4:1176-8, doi:10. 1111/j.1553-2712.1997.tb03708.x.

18. Tanabe P, Ferket K, Thomas R, et al. The effect of standard care, ibuprofen, and distraction on pain relief and patient satisfaction in children with musculoskeletal trauma. 7 Emerg Nurs 2002;28:118-25, doi:10.1067/men.2002.122573.

19. Rogovik AL, Rostami M, Hussain S, et al. Physician pain reminder as an intervention to enhance analgesia for extremity and clavicle injuries in pediatric emergency. 7 Pain 2007;8:26-32, doi:10.1016/j.jpain.2006.05.011.

20. Friedland LR, Pancioli AM, Duncan KM. Pediatric emergency department analgesic practice. Pediatr Emerg Care 1997;3:103-6, doi:10.1097/00006565-199704000-00005.

21. Friedland LR, Kulick RM. Emergency department analgesic use in pediatric trauma victims with fractures. Ann Emerg Med 1994;23:203-7, doi:10.1016/S0196-0644(94)70031-1.

22. Weng YM, Chang YC, Lin YJ. Triage pain scales cannot predict analgesia provision to pediatric patients with long-bone fracture. Am 7 Emerg Med 2010;28:412-7, doi:10.1016/j. ajem.2008.12.035.

23. Alexander J, Manno M. Underuse of analgesia in very young pediatric patients with isolated painful injuries. Ann Emerg Med 2003;41:617-22, doi:10.1067/mem.2003.138.

24. Gilbert EH, Lowenstein SR, Koziol-McLain J, et al. Chart reviews in emergency medicine research: what are the methods? Ann Emerg Med 1996;27:305-8, doi:10.1016/ S0196-0644(96)70264-0.

25. Gearing RE, Mian IA, Barber J, et al. A methodology for conducting retrospective chart review: research in child and adolescent psychiatry. 7 Can Acad Child Adolesc Psychiatry 2006;15:126-34.
26. Liberty Tax. 2008 income tax tables \& tax rates. Available at: http://www.libertytaxcanada.ca/2008-income-tax-tables-taxrates.html (accessed April 2012).

27. Centres for Disease Control and Prevention. Clinical growth charts. Available at: http://www.cdc.gov/growthcharts/clinical_ charts.htm (accessed August 2011).

28. Thompson RW, Krauss B, Kim YJ, et al. Extremity fracture pain after emergency department reduction and casting: predictors of pain after discharge. Ann Emerg Med 2012;60: 269-77, doi:10.1016/j.annemergmed.2012.01.021.

29. Gill M, Drendel AL, Weisman SJ. Parent satisfaction with acute pediatric pain treatment at home. Clin 7 Pain 2013;29: 64-9, doi:10.1097/AJP.0b013e3182454a9e.

30. Dong L, Donaldson A, Metzger R, et al. Analgesic administration in the emergency department for children requiring hospitalization for long-bone fracture. Pediatr Emerg Care 2012;28:109-14.

31. Kozlowski MJ, Wiater JG, Pasqual RG, et al. Painful discrimination: the differential use of analgesia in isolated lower limb injuries. Am 7 Emerg Med 2002;20:502-5, doi:10.1053/ajem.2002.34965.

32. Maimon MS, Marques L, Goldman RD. Parental administration of analgesic medication in children after a limb injury. Pediatr Emerg Care 2007;23:223-6, doi:10.1097/ PEC.0b013e31803f5adc

33. Weng YM, Chang YC, Lin YJ. Triage pain scales cannot predict analgesia provision to pediatric patients with longbone fracture. Am 7 Emerg Med 2010;28:412-7, doi:10.1016/ j.ajem.2008.12.035.

34. Kellogg KM, Fairbanks RJ, O'Connor AB, et al. Association of pain score documentation and analgesic use in a pediatric emergency department. Pediatr Emerg Care 2012;28:128792, doi:10.1097/PEC.0b013e31827687e6.

35. Drendel AL, Brousseau DC, Gorelick MH. Pain assessment for pediatric patients in the emergency department. Pediatrics 2006;117:1511-8, doi:10.1542/peds.2005-2046.

36. Brent AS, Rahman WM, Knarr LL, et al. Reducing cycle times in pediatric emergency medicine. Pediatr Emerg Care 2011;25:307-11, doi:10.1097/PEC.0b013e3181a3482b.

37. Iyer SB, Schubert CJ, Schoettker PJ, et al. Use of qualityimprovement methods to improve timeliness of analgesic delivery. Pediatrics 2011;127:e219-25, doi:10.1542/peds. 2010-0632.

38. Somers LJ, Beckett MW, Sedgwick PM, et al. Improving the delivery of analgesia to children in pain. Emerg Med $\mathcal{Z} 2001$; 18:159-61, doi:10.1136/emj.18.3.159.

39. Ali S, Drendel AL, Kircher J, et al. Pain management of musculoskeletal injuries in children: current state and future directipons. Pediatr Emerg Care 2010;26:518-24, doi:10. 1097/PEC.0b013e3181e5c02b.

40. Morris L, Stulberg D, Stevermer JJ. Fracture pain relief for kids? Ibuprofen does it better. 7 Fam Pract 2010;59:273-5. 